\title{
A linear relation between loudness and decibels
}

\author{
E. C. POULTON \\ Applied Psychology Unit, Cambridge, England
}

\begin{abstract}
A total of 37 uninitiated observers made repeated numerical magnitude judgments of the loudness of a sequence of octave band noises spaced at 1- $\mathrm{dB}$ intervals, from 0 to $5 \mathrm{~dB}$ above a standard of about $80 \mathrm{~dB}(\mathrm{~A})$, which was called 10 . The observers were not instructed to use numbers as ratios. When the median responses are plotted linearly against decibels, they are fitted by straight lines. Each extra decibel adds an average of 1 unit of loudness, range for individual observers 10 through .25 units. This is consistent with the view that the subjectively equal stimulus spacing for the loudness of noise is linear in decibels, and that the observers use numbers linearly in judging the loudness.
\end{abstract}

The investigation illustrated in Figures 1 and 2 was conducted to test the effect of a very small stimulus range of $5 \mathrm{~dB}$ on numerical magnitude judgments. Model A of Poulton's (1968) Figure 1 predicts that as the stimulus range is reduced, the slope of the numerical magnitude judgments will become steeper. This is because the observers' responses do not fully reflect the change in the size of the stimulus range. The investigation was sparked off in 1969 after I read the preprint of the first part of $R$. Teghtsoonian's (1971) review on the range of sensory magnitude (R. Teghtsoonian, 1969).

The investigation is a sequel to Poulton (1969). In the earlier investigation, four separate groups of observers judged the loudness of an octave band of noise over a geometric range of $35 \mathrm{~dB}$. In the sequel, instead of using four different fixed orders for four separate groups of observers, the stimuli were presented in the same fixed order to a single group of observers. As previously, the order of the six stimuli was held constant over two repetitions, to examine the effects of practice unconfounded by changes in asymmetric transfer (Poulton \& Freeman, 1966). The effects of practice are illustrated in Figure 1, summed over all observers. Practice reduces the variability shown by the group medians; but practice does not eliminate the confusion in the middle of the range of stimuli between the variables 2 and $3 \mathrm{~dB}$ more intense than the standard.

\section{Linear Unbiased Relation Between Loudness and Decibels}

As in the 1969 investigation, the observers were not instructed to use numbers as ratios. The group medians of Figure 1 and the medians for individual observers of Figure 2 summed over the three judgments of each stimu-

The author is grateful to the late A. Carpenter for producing the stimuli and recording them on magnetic tape. M. I. Nimmo-Smith advised on statistics. Financial support from the British Medical Research Council is also gratefully acknowledged. Requests for reprints should be addressed to E. C. Poulton, M.R.C. Applied Psychology Unit, 15 Chaucer Road, Cambridge CB2 2EF, England. lus show that there is a linear relation between judged loudness and the intensity of the octave band of noise in decibels.

In Panel A of Figure 1, the median responses are plotted on a linear scale. On the third and last presentation of the set of six stimuli, when the variability is smallest, the medians are well fitted by a straight line using the method of least squares. The exception is the point representing an intensity $2 \mathrm{~dB}$ above the standard, which receives the same median response as the point representing $3 \mathrm{~dB}$ above the standard.

In Panel B of Figure 1, the median responses are plotted on a logarithmic scale. On the third presentation, the medians show a systematic deviation from the best fitting straight line. The function is slightly concave downward. Thus, the $\log -\log$ plot of Panel B is not the appropriate plot for giving a straight line function. The relation between loudness and intensity is linear in decibels.

Figure 2 shows a similar linear relation for the medians of individual observers, averaged over the three judgments of each stimulus. Using the method of least squares, alt but 4 of the 37 individual functions appear to be fitted as well by a straight line as by a simple curve. However, functions 19 and 20 look as if they would be fitted better by a concave downward curve, whereas functions 21 and 22 look as if they would be fitted better by a concave upward curve. Plotting the median responses on a log scale would improve the fit of a straight line to the two concave upward functions, but would worsen the fit to the two concave downward functions. Taken overall, the individual observers show a more or less linear relation between loudness and noise level in decibels, like the median observers of Figure 1.

The slopes of the individual functions in Figure 2 indicate the average number of units of loudness which the observers judge to separate one stimulus from the next largest stimulus. Observer 1 in Panel A appears to use units of 10, whereas Observer 2 uses units of 5. Most of the observers in Panel B probably use units of 2 . The median observers of Figure 1, and many of the observers 


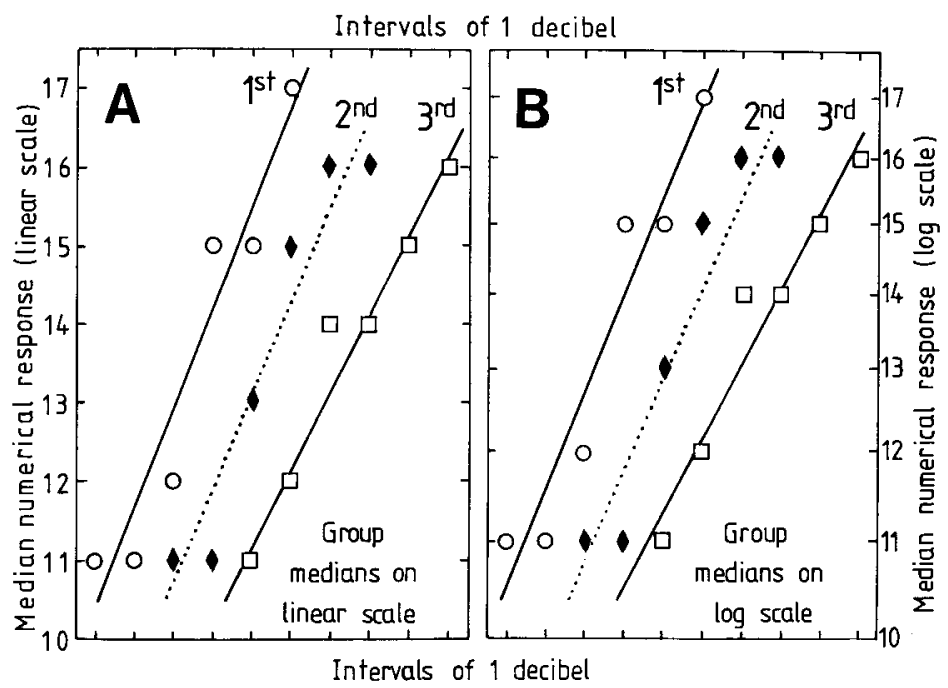

Figure 1. The least squares linear relation between judged loudness and the intensity of the noise in decibels. In Panel A, the median numerical responses of the 37 observers are plotted on a linear scale. On the third presentation, the function is well fitted by a straight line. In Panel B, the responses are plotted logarithmically. On the third presentation, the function is concave downward.

in Panel C of Figure 2, use units of 1.0. The observers in Panel D appear to use units of $1.0, .5$, or .25. Provided the observers use numbers linearly, it does not matter how many units of loudness are judged to separate one stimulus from the next largest stimulus. One number of units is good as another, just as differences in length can be measured in centimeters or millimeters.

An analysis of the very first judgments of the observers

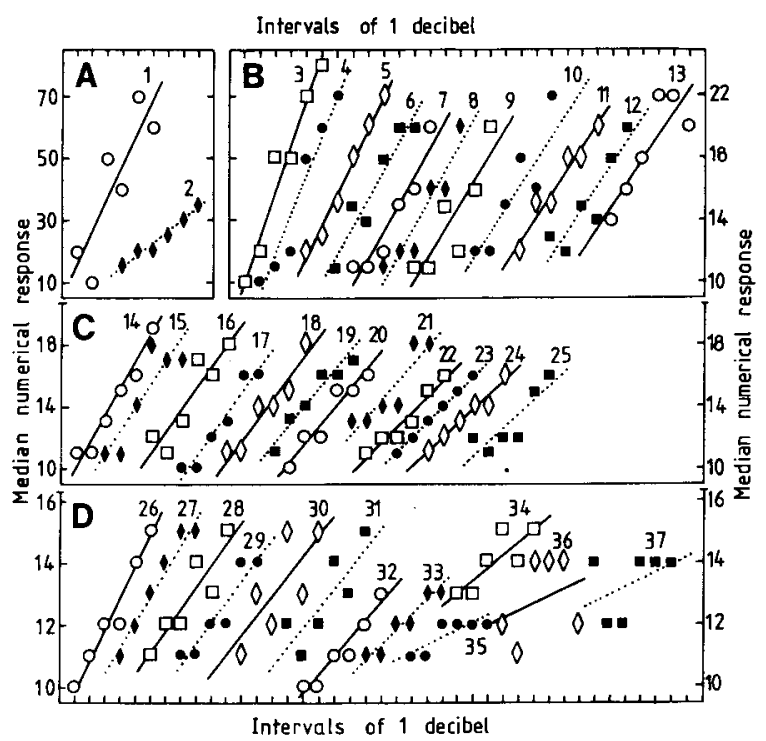

Figure 2. The median numerical responses of the individual observers plotted linearly against the noise intensity in decibels. Apart from functions 19 through 22 , all the functions appear to be fitted as well by a straight line as by a simple curve. Note the different scale on the ordinate of each panel. in the 1969 investigation shows a similar linear relation between the median judgments of loudness and the intensity of the octave band of noise measured in decibels. Rows 2 and 3 of Figure 3 (Poulton, 1982) show the distributions of the very first judgments of the variable $20 \mathrm{~dB}$ above the standard called 1.0 . Using numbers linearly, the medians of 6 and 7 make one unit of loudness correspond to 4 and $3.3 \mathrm{~dB}$, respectively.

Row 1 of Figure 3 shows that the variable $5 \mathrm{~dB}$ above the standard receives a median numerical response of 2.0. Thus, here one unit of loudness corresponds to $5 \mathrm{~dB}$. Since the observers stick almost exclusively to whole numbers, this is consistent with the values of 4 and $3.3 \mathrm{~dB}$ per unit of loudness for the variable $20 \mathrm{~dB}$ above the standard.

\section{Logarithmic Response Bias}

Predicting from the medians in the top three rows of Figure 3 , the variable $35 \mathrm{~dB}$ above the standard in the bottom row should receive a median judgment of 11 . Instead, it receives a median of 20 . The figure shows that this is because above 10 most observers judge in 10 s, instead of using digit intervals as they do below 10 (Banks \& Hill, 1974). This produces a logarithmic response bias, which transfers to the subsequent judgments of less intense stimuli (Poulton, in press, Figure 6.5).

The logarithmic response bias is produced by a step change in the number of digits used as responses (Poulton, 1979, p. 783). There is no logarithmic response bias in Figures 1 and 2, because there is no step change. The standard is called 10 , and the largest individual response ever given is only 80 . Hence the linear relation between the numerical magnitude judgments of loudness and decibels, as in the top 3 rows of Figure 3. 


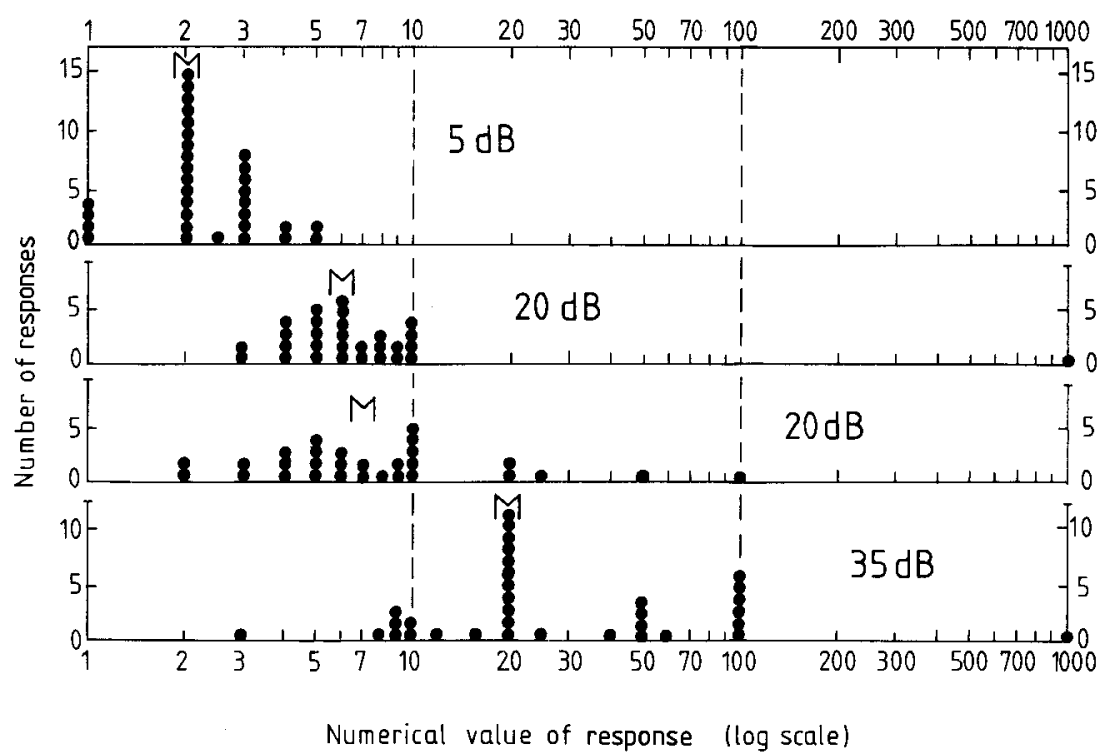

Figure 3. Linear responses and the logarithmic response bias in individual very first multiple numerical judgments of the loudness of noise against a less intense standard called 1.0. Each row is for a separate group of between 28 and 33 uninitiated observers. The medians are marked $M$. The decibel value printed in each row represents the increase in intensity of the stimulus above the standard of about $65 \mathrm{~dB}$. Numerical judgments smaller than 10 usually occur at digit intervals. Numerical judgments greater than 10 tend to be multiples of 10, owing to the logarithmic response bias. (After Poulton, 1982, Figure 5.)

\section{Difference Between Noises and Pure Tones}

The linear relation in Figures 1 and 2 between loudness and decibels applies only to noise stimuli, in which the sensitivity per decibel remains constant at suprathreshold levels (Harris, 1950; Miller, 1947). The relation can be described as a linear relation between loudness and sensitivity. Pure-tone stimuli show an apparent logarithmic response bias (Poulton, in press, chap. 6), because the sensitivity per decibel increases with sound pressure level (Houtsma, Durlach, \& Braida, 1980; Jesteadt, Wier, \& Green, 1977). It is necessary to correct for the increase in sensitivity per decibel in order to obtain the relation between loudness matches and sensitivity which corresponds to the linear relation of Figures 1 and 2 (Houtsma et al., 1980).

The difference between noise stimuli and pure tone stimuli is reflected in the nonlinear relation between noise and pure tones, which is found by direct loudness matching. Zwicker (1958) gets 20 observers to match a $1-\mathrm{kHz}$ tone and broadband white noise. Scharf (1959) gets 8 observers to match a $1.5-\mathrm{kHz}$ tone and a $1.6-\mathrm{kHz}$ band of white noise centered on $1.5 \mathrm{kHz}$. Both investigators find a similar nonlinear relation (see Poulton, in press, Figure 4.3).

\section{Stimulus Range Equalizing Bias}

The investigation illustrated in Figures 1 and 2 turns out not to be appropriate for studying the stimulus range equalizing bias. The observers use numbers linearly, not as ratios. Thus, it is not appropriate to compare the me- dian geometric response range with the geometric response ranges of the 1969 investigation.

The appropriate comparison would use the arithmetic response ranges of the two investigations on the very first judgment. But, unfortunately, the arithmetic response ranges are not comparable. In the investigation of Figures 1 and 2, the standard is given a modulus number of 10 in order to avoid the use of decimals or fractions in responding, whereas in the 1969 investigation the standard has a modulus of 1.0.

The Teghtsoonians' (R. Teghtsoonian, 1973, Figure 4 and Table 1; R. Teghtsoonian \& M. Teghtsoonian, 1978, Figure 1) investigation of the stimulus range equalizing biases in numerical magnitude judgments of loudness appears to run into similar difficulties. As in the investigation of Figures 1 and 2, the observers are not instructed to use numbers as ratios. But it is not possible to compare the Teghtsoonians' arithmetic response ranges, because each observer selects her own modulus number for the standard.

The Teghtsoonians present separate groups of 12 women undergraduates with stimulus ranges of $5,10,20$, or $40 \mathrm{~dB}$. If the median undergraduates were to use numbers logarithmically, one would expect a similar proportional change in the size of exponent in comparing stimulus ranges of 5 and $10 \mathrm{~dB}$, as in comparing stimulus ranges of 20 and $40 \mathrm{~dB}$. Yet, increasing the stimulus range from 5 to $10 \mathrm{~dB}$ reduces the median exponent to $74 \%$ of its size, whereas increasing the stimulus range from 20 to $40 \mathrm{~dB}$ reduces the exponent to only $98 \%$ of its size. This 
would happen if the median undergraduates were to follow the median observers of Figure 3 and use numbers linearly for stimulus ranges between 5 and $20 \mathrm{~dB}$, but use numbers logarithmically for the largest stimulus range of $40 \mathrm{~dB}$. The logarithmic response bias would then counteract the stimulus range equalizing bias in comparing the effects of the 20 - and $40-\mathrm{dB}$ stimulus ranges.

The Teghtsoonians test the fit of their logarithmic response model to the responses of individual students. But they use as a minimum acceptable coefficient of determination an $\mathrm{r}^{2}$ of only .8 (R. Teghtsoonian \& M. Teghtsoonian, 1978, p. 307). With an $n$ of only 6 points on each function, equally spaced in decibels, the minimum possible coefficient of determination is $3 /(n+1)$ $=.43$. To achieve this minimum value, the students have simply to rank order the six stimuli correctly by magnitude (Coleman, Graf, \& Alf, 1981). Thus, the Teghtsoonians' minimum acceptable $r^{2}$ of only .8 does not indicate a particularly good fit to their logarithmic response model. This suggests that many of their undergraduates' so-called power functions may well be produced by using numbers linearly, instead of as ratios.

For the groups with median undergraduates who use numbers linearly, it is not appropriate to calculate the median exponents from the geometric response ranges. Nor would it be appropriate to use the arithmetic response ranges, because each undergraduate selects her own modulus number for the standard. If this is so, the Teghtsoonians' investigation faces difficulties similar to those encountered in the investigation of Figures 1 and 2 . It is not appropriate for studying the stimulus range equalizing bias for loudness.

\section{REFERENCES}

BaNKS, W. P., \& HiLl, D. K. (1974). The apparent magnitude of number scaled by random production. Journal of Experimental Psychology, 102, 353-376.

Coleman, B. J., Graf, R. G., \& Alf, E. F. (1981). Assessing power function relationships in magnitude estimation. Perception \& Psychophysics, 29, 178-180.

HARRIS, J. D. (1950). The effect of sensation-levels on intensive discrimination of noise. American Journal of Psychology, 63, 409-421.

Houtsma, A. J. M., Durlach, N. I., \& Braida, L. D. (1980). Intensity perception XI. Experimental results on the relation of intensity resolution to loudness matching. Journal of the Acoustical Society of America, 68, 807-813.

JesteadT, W., Wier, C. C., \& Green, D. M. (1977). Intensity discrimination as a function of frequency and sensation level. Journal of the Acoustical Society of America, 61, 169-177.

MiLler, G, A. (1947). Sensitivity to changes in the intensity of white noise and its relation to masking and loudness. Joumal of the Acoustical Society of America, 19, 609-619.

Poulton, E. C. (1968). The new psychophysics: Six models for magnitude estimation. Psychological Bulletin, 69, 1-19.

Poulton, E. C. (1969). Choice of first variables for single and repeated multiple estimates of loudness. Journal of Experimental Psychology, 80, 249-253.

Poulton, E. C. (1979). Models for biases in judging sensory magnitude. Psychological Bulletin, 86, 777-803.

Poulton, E. C. (1982). Biases in quantitative judgments. Applied Ergonomics, 13, 31-42.

Poulton, E. C. (in press). Bias in judgment. San Francisco: Academic Press.
Poulton, E. C., \& Freeman, P. R. (1966). Unwanted asymmetrical transfer effects with balanced experimental designs. Psychological Bulletin, 66, 1-8.

SCHARF, B. (1959). Loudness of complex sounds as a function of the number of components. Journal of the Acoustical Society of America, 31, 783-785.

TEGHTSOONIAN, R. (1969, April). The range of sensory magnitude. Unpublished manuscript.

Teghtsoonian, R. (1971). On the exponents in Stevens' law and the constant in Ekman's law. Psychological Review, 78, 71-80.

Teghtsoonian, R. (1973). Range effects in psychophysical scaling and a revision of Stevens' law. American Journal of Psychology, 86, 3-27.

Teghtsoonian, R., \& Teghtsoonian, M. (1978). Range and regression effects in magnitude scaling. Perception \& Psychophysics, 24, 305-314.

ZWICKER, E. (1958). Über psychologische und methodisch Grundlagen der Lautheit. Acustica, 8, 237-258.

\section{APPENDIX ON METHOD}

\section{Observers}

The observers, 23 women and 14 men, were members of a panel maintained at the Applied Psychology Unit in Cambridge. Their ages ranged from 18 to 73 years, with a median age of 49 . They were paid for their services. None had previously judged sensory magnitudes. Two additional men, aged 63 and 77, were discarded because they did not provide a complete set of responses.

\section{Stimuli}

White noise of limited amplitude was passed through an octave filter with cutoffs at 700 and $1400 \mathrm{~Hz}$ of $20 \mathrm{~dB}$ per octave. The two stimuli of a pair each lasted $.78 \mathrm{sec}$, with an interval of $1.07 \mathrm{sec}$ between them. Sound pressure levels were changed using a Muirhead attenuator. The stimuli were recorded on a Vortexion magnetic tape recorder (type CBL). The tape recording was played back using a Ferrograph recorder. The stimuli were fed to a Goodmans Axiom 22 loudspeaker, mounted in a wooden enclosure of $.17 \mathrm{~m}^{3}$, which was resonant at $40 \mathrm{~Hz}$.

The loudspeaker was placed against the middle of one of the long sides of the test room, which was approximately rectangular with $4.9 \times 7.6 \mathrm{~m}$ sides and a height of $3.2 \mathrm{~m}$. The room contained between 14 and 16 observers seated at tables. The sound pressure level of each stimulus was measured during the investigation using the A scale of a Dawe soundlevel meter set to give the fast response. When the sound-level meter was placed at the different positions normally occupied by an observer, the average sound pressure level of the stimuli changed by about $3 \mathrm{~dB}$, depending on the exact location of the meter and the number of people in the room. However, the differences between the standard and the variables did not change. Only the average levels will be referred to from now on. The ambient noise level in the room never fell below $38 \mathrm{~dB}(\mathrm{~A})$ re $20 \mu \mathrm{N} / \mathrm{m}^{2}$.

\section{Experimental Design}

The 6 variables were always presented in the same order: 82,84 , $81,85,83$, and $80 \mathrm{~dB}(\mathrm{~A})$ re $20 \mu \mathrm{N} / \mathrm{m}^{2}$. The standard presented before each variable had a sound pressure level of $80 \mathrm{~dB}(\mathrm{~A})$. The first pair of stimuli was repeated once. The remaining pairs were not repeated. Each pair was followed by ample time, about $7.5 \mathrm{sec}$, for the observers to write down their numerical estimates.

The sequence of 6 variables was repeated twice, making 18 variables in all. The observers were not told that the sequence was repeated. Their response sheets had spaces for the answers to the first 8 variables on the front, and for the last 10 variables on the back. This was done to conceal the structure of the sequence.

\section{Procedure}

Each observer was handed a stenciled answer sheet with 8 spaces at the bottom, one below the other, labeled (a) to (h) and 10 spaces on the back labeled (i) to (r). At the top, the sheet carried the following instructions: "You will hear two sounds, the second louder than the first. If the loudness of the first sound is called 10, what (larger) num- 
ber describes the loudness of the second sound? Please write down your answer in the space (a) below.'

Before reading the instructions, the investigator pointed to a vertical line, $15 \mathrm{~cm}$ high, that was drawn in the middle of a blackboard, $85 \mathrm{~cm}$ high and $110 \mathrm{~cm}$ wide, and said: "I have drawn a line on the board. We can call its length 10 units. Suppose I draw a longer line. Its length will be more than 10 units. You could estimate the length in units. I want you to do this, only with sounds. I will play a sound. We can call its loudness 10 units. I will then play you a louder sound. Its loudness will be more than 10 units. I want you to estimate its loudness in units. But first listen to some of the sounds. See how they differ in loudness."

The investigator then played the sequence of variable sounds twice, with an additional variable of $81 \mathrm{~dB}(\mathrm{~A})$ inserted between the two sequences. Presenting all the sounds first helped the observers to discriminate between their loudnesses. Without this initial presentation, some observers said that all the sounds were about equally loud, because the maximum difference was only $5 \mathrm{~dB}$.
Finally the investigator read aloud the instructions typed at the top of the answer sheet, and answered questions. Groups in which an observer asked about the upper limit were told that there was no upper limit. It was up to each observer to judge the loudness, and to write down the corresponding number.

The observers were told that the first pair of sounds would be repeated. The first presentation was to let them know what they had to listen to. The second time, they had to make a judgment and write it down. The second pair of sounds was not presented until everyone had written down his or her first answer. The same applied to the third pair of sounds. After this, the tape recorder was not turned off between presentations, except after the eighth pair, when the observers had to turn over their answer sheets. The investigator sat at one of the tables with a soundlevel meter. He noted down the sound pressure levels of the stimuli.

(Manuscript received December 9, 1983; revision accepted for publication June 22, 1984.) 